\title{
El servicio de biblioteca en la es- fera del poder ejecutivo: el caso de las bibliotecas presidenciales
}

\author{
Felipe Meneses Tello *
}

Artículo recibido:

6 de agosto de 2010.

Artículo aceptado:

11 de octubre de 2010.

\section{RESUMEN}

Se analiza el asunto de las instituciones bibliotecarias al servicio directo del Poder Ejecutivo. El problema se ubica en el marco de la compleja relación que existe entre biblioteca y poder público, y en consecuencia entre biblioteca y Estado. Como referente se estudia la biblioteca presidencial estadounidense. Empero, el autor va más allá del modelo de la biblioteca presidencial de los Estados Unidos, y reflexionar por qué el servicio de este tipo de centro bibliotecario debe existir: para apoyar los actos políticos que un presidente de la República (como jefe de Estado y como jefe de gobierno) realiza en cumplimiento de sus facultades y las obligaciones que le confiere la ley.

* Facultad de Filosofía y Letras de la UNAM. fmeneses@correo.unam.mx

INVESTIGACIÓN BIBLIOTECOLÓGICA, Vol. 24, Núm. 52, septiembre/diciembre, 2010, México, ISSN: 0187-358X. pp. 29-62 
Palabras clave: Biblioteca presidencial; Presidencia de la República; Jefe del Estado; Jefe del Gobierno; Poder Ejecutivo; Estado.

\section{ABSTRACT}

Library services in the realm of executive power: the case of presidential libraries

Felipe Meneses Tello

This paper analyzes the issues arising from library institutions in the direct service of the executive branch. The problem lies within the framework of the complex relationship that exists between library and public power, and by extension between library and the state. As a point of reference, US presidential libraries are examined. The author goes beyond the model of the US presidential library; however, to reflect upon why this kind of library is essential to supporting the political actions, in the fulfillment of the powers and duties conferred by law, of the President of the Republic as Chief of State and the government.

Key words: Presidential library, Presidency of the Republic, Chief of State, Head of Government, Executive Power, State.

\section{INTRODUCCIÓN}

E ste tema presenta la dificultad concerniente a la escasa literatura bibliotecológica que existe al respecto y por tanto a la ausencia de puntos de vista teórico-prácticos que permitan formular una unidad teórica consistente acerca del nexo específico de estudio: bibliotecas y órgano ejecutivo. El problema se agudiza cuando las aportaciones en este tipo de institución bibliotecaria se refieren particularmente a una nación tan compleja como los Estados Unidos de Norteamérica. En virtud del valor político, social y cultural que debe tener una «biblioteca presidencial» en los Estados democráticos de Derecho, es comprensible hacer esfuerzos por crear avances teóricos que nos permitan dilucidar el interés que ese centro bibliotecario — en el seno de los Estados contemporáneos administrados bajo el sistema presidencial—, puede tener 
en el marco especial de una bibliotecología política. En concordancia con las categorías que la doctrina de la División de Poderes reparte el poder político, esa rama de la bibliotecología no puede evadir el problema teórico que entraña la biblioteca presidencial en el entramado de la forma estatal conocida como Estado Federal. Desde esta perspectiva, el tópico de las instituciones bibliotecarias al servicio directo del ejecutivo se ubica en el marco de una relación más compleja: biblioteca(s) y Estado(s) a través de la cual se percibe la conexión entre biblioteca (s) y poder (es) público(s).

Para desarrollar nuestro discurso en torno de las bibliotecas del Poder Ejecutivo se estudiará como punto de partida el concepto de «biblioteca presidencial» desde la óptica estadounidense, la cual a nuestro juicio es la más desarrollada, aunque esta práctica y teoría no se ajustan a lo que se pretende considerar aquí como una biblioteca presidencial en activo. Por otro lado se argumenta la necesidad de contar con este tipo de centro bibliotecario para asistir tanto a la Jefatura de Estado como a la de Gobierno durante el periodo que ejerce una persona como primer mandatario de una nación. En todo caso se razona por qué el servicio de biblioteca presidencial puede y debe existir en el marco del régimen presidencial, para apoyar los actos políticos que se le confieren al Titular del órgano ejecutivo de la República. Así, yendo más allá del modelo de la biblioteca presidencial de los Estados Unidos se intenta hilar un discurso que apunte hacia la construcción teórica de una biblioteca presidencial en la práctica plena de asistir al presidente de la República durante su gestión.

Pero en virtud de que se trata de un discurso teórico y no empírico, el contenido de este artículo no tiene la pretensión de ajustarse a un país en particular, antes bien, su objetivo es exponer la idea de crear, si no existe como tal, o continuar mejorando el desarrollo, en caso de que ya exista, el servicio activo de biblioteca presidencial en el seno del Poder Ejecutivo. En todo caso, se aportan nociones que explican la importancia y el influjo que puede tener este tipo de institución bibliotecaria en el universo del Estado limitado por el derecho y en la actuación del poder político central.

\section{LA BIBLIOTECA PRESIDENCIAL ESTADOUNIDENSE}

Como sucede con el caso de las bibliotecas parlamentarias son varios los diccionarios o léxicos de referencia en el campo de la bibliotecología en los que el término biblioteca presidencial está ausente. Esta omisión, en contraste con las bibliotecas al servicio de los Parlamentos, es aún más notoria, motivo por el que resulta difícil conceptuar ese género de centro bibliotecario. Sin embargo 
se debe hacer el intento por establecer una definición operativa. Comencemos por algunas fuentes. Desde una arista general, para Prytherch, ${ }^{1}$ las «presidential libraries» son "los documentos de cada presidente de los Estados Unidos", con los cuales se forma una "biblioteca de investigación”. En la International encyclopedia of information and library science, edición a cargo de Feather y Sturges, ${ }^{2}$ se hace mención al término «presidencial libraries» como «research libraries», las cuales contienen las colecciones documentales de cada presidente de los Estados Unidos. Reitz considera la «presidencial library» como una «special library» que contiene los documentos de un presidente de los Estados Unidos, localizada generalmente en o cerca del lugar de nacimiento o de la residencia anterior a su elección.

Observamos así que la biblioteca presidencial en esas fuentes especializadas de referencia asocian la explicación del término a los centros bibliotecarios que se forman después del periodo del ejercicio político de un determinado presidente estadounidense, por ende, la expresión en cuestión la circunscriben posteriormente al cargo público y a un país. Debido a esta noción limitada, esas instituciones bibliotecarias representan, como apunta Reitz, "un sistema substancial de monumentos a los presidentes", idea que coincide con Cochrane ${ }^{4}$ quien asevera que "esos monumentos sirven más como museos y archivos repositorios" que como bibliotecas, por lo que advierte, son "presidenciales, sí; bibliotecas, realmente no".

Ante tal desavenencia resulta pertinente tomar en cuenta lo que en el sitio Web oficial de las bibliotecas presidenciales de los Estados Unidos se asienta:

éstas no son bibliotecas tradicionales, sino repositorios para preservar y hacer disponibles los documentos, los registros y otros materiales históricos de los presidentes de los Estados Unidos. ${ }^{5}$

En este orden de ideas, Khan llegó a estimar, a fines de la década de los años 50 del siglo pasado, varios aspectos con cierto matiz teórico al aseverar, en torno de la biblioteca presidencial estadounidense, lo siguiente:

1 Ray Prytherch, Harrod's librarians' glossary, England: Gower, 1990, p. 492.

2 John Feather; Sturges, Paul, (Eds.) International encyclopedia of information and library science, London : Routledge, 1997, p. 372.

3 Joan M. Reitz, Dictionary for library and information science, Westport, Connecticut : Libraries Unlimited, 2004, p. 562.

4 Lynn Scout Cochrane, "Presidential, yes; libraries, not really", en American Libraries, 33 (5) (2002): 59-62.

5 NARA. Presidential Libraries. Presidential Libraries of the National Archives and Records Administration, (citado el 29 de julio de 2010), disponible en Internet: http://www.archives. gov/presidential_libraries/about/about.html 
Como su crecimiento ha sido acogido y son ahora administradas no por bibliotecarios sino por archivistas, muchos bibliotecarios no pueden entender completamente los orígenes, las características especiales y las razones convincentes de este nuevo tipo de institución. Estas instituciones, aunque llamadas bibliotecas, son tanto archivos y museos como bibliotecas. Con todo, - agrega Khan - los bibliotecarios han tomado siempre un interés intenso en estas instituciones, y no es nada extraño que entre los bibliotecarios, los bibliotecarios especiales sean los que están más interesados. ${ }^{6}$

Así, desde una perspectiva taxonómica, este autor advierte que

las bibliotecas presidenciales se relacionan más de cerca con la clase de bibliotecas llamadas 'especiales' que cualquier otra clase de biblioteca, y sus colecciones de libros constituyen ciertamente bibliotecas especiales. ${ }^{7}$

Recordemos que la expresión «special library», según Johns, ${ }^{8}$ contempla dos categorías conceptuales: a] bibliotecas especializadas propiamente dichas (teológicas, jurídicas, médicas, científicas, etcétera) y b] especiales (instaladas para ancianos, enfermos, presos, etcétera).

Continuando con nuestro análisis, en el mismo cuadrante geopolítico, Lovely ${ }^{9}$ colige que la expresión de bibliotecas presidenciales es "un término amplio que abarca almacenes de archivo de fuentes primarias, de colecciones bibliotecarias de materiales secundarios, objetos de museo y conmemorativos". En este sentido y para este autor "las bibliotecas presidenciales son contribuciones únicas e invaluables para la educación patriótica e histórica de muchos" ciudadanos. La función de educación que desempeñan esos recintos también la reconoce Dennis al hacer notar que esas:

bibliotecas no son monumentos, [dedicados] exclusivamente, a hombres individuales. Son edificios que contienen documentos, los cuales son registros vitales de nuestra historia del país, y atendidas por profesionales que están deseosos de servir a estudiantes de nuestra manera de vida americana [...] las bibliotecas presidenciales no se centran solamente en la atención de la presidencia y en los hombres

6 Herman Kahn, “The presidential library - a new institution”, en Special Libraries, 50 (3), (March 1959): 106-113.

7 Ibid., p. 106.

8 Ada Winifred Johns, Special libraries: Development of the concept, their organizations, and their services, Metuchen : Scarecrow, 1968, pp.13 y 21.

9 Sister Louise Lovely, "The evolution of presidential libraries", en Government Publications Review, 6 (1), (1979): 27-35. 
que han sido presidentes, sino también reflejan el pensamiento de los ciudadanos americanos a través de su correspondencia con ellos. ${ }^{10}$

La función de investigación también es relevante para esta autora al afirmar que "La biblioteca personal del presidente demuestra el carácter intelectual del hombre, y está allí en su biblioteca presidencial para que el investigador lo estudie". ${ }^{11}$ Así, es regla general que esas instituciones funjan como recintos que guardan parte de la historia de quienes han representado el Poder Ejecutivo de los Estados Unidos.

Con base en las ideas anteriores podemos distinguir que el objeto de estudio en cuestión se puede considerar como: 1] biblioteca especial, 2] biblioteca de investigación, 3] biblioteca-museo y 4] biblioteca-archivo. Con base en estas dos últimas categorías, Cochrane insiste y afirma categóricamente que en los Estados Unidos, las "bibliotecas presidenciales actualmente son museos y repositorios de archivo, no bibliotecas en el sentido acostumbrado". ${ }^{12}$ Estamos entonces ante un fenómeno político-cultural, cuyo marco conceptual configura un conjunto de recintos que testimonian el patrimonio bibliográfico y documental de quienes han fungido como sujetos de la función ejecutiva realizada por la Jefatura del Estado y Gobierno de los Estados Unidos. $\mathrm{El}$ vasto acervo de biblioteca y archivo que albergan esas instituciones materializa la dirección política que caracteriza la forma presidencial de gobierno; es decir, aporta la documentación especial y especializada que entraña las funciones de gobernar desde el punto de vista del Poder Ejecutivo.

Las bibliotecas formadas con las colecciones bibliográfico-documentales de los presidentes estadounidenses, y construidas con fondos privados y mantenidas con fondos públicos, comenzaron a crearse durante el siglo XX, concretamente a finales de la década de los años treinta. Veit ${ }^{13}$ afirmará que las "bibliotecas presidenciales como nosotros las conocemos hoy son relativamente nuevas creaciones". En este plano de novedad, Kamath ${ }^{14}$ nos aporta dos antecedentes de particular importancia: 1] el concepto de biblioteca presidencial se originó en los Estados Unidos a partir de la creación de la Biblioteca del Presidente Franklin D. Roosevelt (1933-1945), mandatario que el 4 de julio de 1938, día de la Independencia de los Estados Unidos, anunció planes para construir la biblioteca que contendría los documentos relacionados con su

10 Ruth Dennis, "Presidential libraries", en Encyclopedia of library and information science, 23. New York : Marcel Dekker, 1978, p. 230.

11 Ibid., p. 233.

12 Lynn Scout Cochrane, op. cit., p. 59.

13 Fritz Veit, Presidential libraries and collections, New York: Greenwood Press, 1987, p. 1.

14 P. M. Kammath, "Presidential libraries of United States", en Herald of Library Science, 33 (3-4) (July-October 1994): 200-204. 
ejercicio presidencial, y 2] quince años más tarde, el Congreso de los Estados Unidos institucionalizaría el concepto de bibliotecas presidenciales mediante la Presidential Libraries Act de 1955. También, Yakel"15 asevera que el "Presidential Library System fue establecido en 1939 por el presidente Franklin D. Roosevelt. Él donó tanto sus expedientes presidenciales como los documentos personales al gobierno de la Estados Unidos”. En concordancia con esto, esta autora afirma que estas "bibliotecas" son una combinación de documentos públicos y vidas privadas. Esta política sobre este tipo de bibliotecas ha evitado la dispersión de los documentos presidenciales al finalizar el mandato, con lo que ha ayudado a preservarlos.

Otro antecedente importante que advierte Cochrane ${ }^{16}$ es que el bibliotecario Randolph G. Adams, director de la William I. Clements Library, perteneciente a la University of Michigan, fue el primero en probar el término «biblioteca», citando el ejemplo de la Herbert Hoover Library of War, Revolution and Peace, establecida en 1919 en el campus de la Stanford University. Colección bibliográfica que en la década de los sesenta, del siglo pasado se convertiría en la biblioteca-museo presidencial y pasaría así a formar parte de ese sistema bibliotecario federal. Con base en esta práctica comenzarían a figurar otros términos en la literatura bibliotecológica de ese país, tales como «presidential papers», «archival presidential libraries», «federal presidential library»y, de este modo se formalizaría en la práctica el «Presidential Library System» o el «Federal Presidential Library System». Constituido a la fecha por trece bibliotecas presidenciales, se le considera a este sistema como una «nationwide network of libraries», administrada por la Office of Presidential Libraries, la cual forma parte de la agencia gubernamental federal denominada National Archives and Records Administration (NARA). ${ }^{17}$

Con la intención de plantear una primera definición acotada de acuerdo con el modelo de las bibliotecas presidenciales estadounidenses, la biblioteca presidencial es posible conceptuarla, por un lado, como una biblioteca-museoarchivo personal y, por el otro, como una biblioteca politico-bistórica especial en la esfera de las instituciones gubernamentales federales de los Estados Unidos, teniendo como propósito proteger y preservar las colecciones documentales referentes a la vida y administración de los presidentes de esa nación; así como proporcionarle al ciudadano estadounidense el acceso a los materiales históricos y políticos de la vida y el ejercicio presidencial, correspondientes al personaje

15 Elizabeth Yakel, Presidential libraries: merging public records and private lives, OCLC Systems EServices, 23 (39), (2007): 238-241.

16 Lynn Scout Cochrane, op. cit., p. 59.

17 NARA. Presidential Libraries, (citado 29 de julio de 2010), disponible en Internet: http:// www.archives.gov/presidential-libraries/index.html 
que tuvo la función de Jefe de Estado y del Gobierno, incluidos los documentos relacionados con el funcionamiento gubernamental durante el periodo que cubre los acervos de la biblioteca.

Este concepto se asocia en cierto sentido con los niveles de transparencia que el Estado democrático de Derecho debe garantizarle a la ciudadanía, pues los mecanismos de adquisición de conocimiento sobre los aciertos y los errores del pasado, cometidos por los representantes del Poder Ejecutivo, particularmente por el Jefe de Estado y del Gobierno, así como por sus secretarios o ministros en el desempeño de las facultades que les otorga la Constitución, son un referente inherente al acceso público a la información gubernamental. Empero, se trata de una noción que tiene límites y que por lo tanto no puede ser aceptada universalmente. Esta idea definitoria se ciñe, como podemos apreciar, a la disposición de ofrecerle al público bibliotecas presidenciales personales alusivas a algunos políticos que han tenido a cargo el Poder Ejecutivo de un país en concreto. Con todo, esta concepción puede ser central para un debate actual sobre las funciones y las actividades básicas de esas bibliotecas-archivo, vestigios monumentales de quienes han representado el Poder Ejecutivo de una nación con sistema presidencial.

Sin embargo en virtud del panorama que aquí se pretende esbozar, el término estadounidense de biblioteca presidencial, dado su modelo reducido, no se ajusta a lo que en torno de esta expresión se piensa puede ser un hilo conductor para pensar en la presencia del servicio de biblioteca en el ámbito de la dinámica del quehacer político que se lleva a cabo en la estructura de la Presidencia de la República. Al margen de las concepciones sociales y políticas acerca de las bibliotecas presidenciales estadounidenses, la biblioteca para la asistencia de ese órgano ejecutivo gubernamental representa una forma bibliotecológico-política que, a diferencia de la biblioteca parlamentaria, ${ }^{18}$ no ha sido desarrollada teóricamente a la luz del derecho político y de la ciencia política.

Esforcémonos, pues, en construir un discurso teórico que nos permita descubrir y argumentar la importancia, el influjo y, en todo caso, la necesidad que existe de una biblioteca presidencial en, para y durante el poder de dirección política que realiza, por un lado, el Órgano de la Presidencia de la República y, por el otro, el Titular de la misma, para que con base en este análisis se logre sugerir una definición más amplia de la biblioteca que asiste (o que puede y debería asistir) al Poder Ejecutivo.

18 Felipe Meneses Tello, "La composición orgánica de las bibliotecas parlamentarias: una perspectiva global”, en Investigación Bibliotecológica, (México). Vol. 22, núm. 46 (sept./dic. 2008), pp. 187-222. 


\section{LA BIBLIOTECA AL SERVICIO DEL ÓRGANO DE LA PRESIDENCIA DE LA REPÚBLICA}

En relación con la institución presidencial, Villa ${ }^{19}$ distingue que ésta muestra dos vías de la vida política; a saber, "la del papel del dirigente que lleva a cabo la práctica de la institución y la de la estructura orgánica que lo enmarca y delimita". De esta manera se trata de analizar, primero, el carácter institucional de la Presidencia de la República. Es decir que se intenta explicar aquí las relaciones que pueden existir entre el servicio de biblioteca presidencial con dos entidades políticas que, como se funden y confunden en la forma presidencial de gobierno, hacen indispensable, para sistematizar nuestro discurso, que les dediquemos un análisis por separado: 1] Jefatura del Estado y 2] Jefatura del Gobierno. La diferenciación estructural de esta división de poder institucionalizado resalta al observar la función ejecutiva que tiene la dirección política que esos órganos del aparato presidencial desempeñan. La estructura institucional del Poder Ejecutivo, entendida ésta como la configuración de los órganos que ejercen el poder en el contexto de esa rama de la estructura institucional del Estado, nos permitirá identificar la dimensión, necesidad e influencia que las bibliotecas presidenciales pueden tener entre quienes gobiernan y aplican el poder del Estado.

El principio de información ${ }^{20}$ en el que es posible apoyar la teoría de la biblioteca parlamentaria dentro del marco de la División de Poderes, es factible también tenerlo en cuenta desde el punto de vista de la Presidencia de la República. En este sentido, el principio de información se entiende como el que apunta de una presidencia desinformada o escasamente informada hacia un órgano presidencial informado, y éste hacia una presidencia republicana cada vez mejor informada. Esto significa que la biblioteca presidencial debe existir para que la toma de decisiones políticas, en el nivel tanto de la Jefatura del Estado como de la Jefatura de Gobierno, se hagan sistemáticamente con base en la información política necesaria que los servicios bibliotecarios presidenciales, plenamente en activo, puedan ofrecer tanto al Jefe del Estado y Gobierno como al personal de apoyo a esas dos entidades políticas, y el cual constituye parte importante del cuerpo colectivo del Gobierno.

19 Manuel Villa Aguilera, La Institución presidencial: el poder de las instituciones y los espacios de la democracia, México: Coordinación de Humanidades, unAm, Miguel Ángel Porrúa, 1987, p.15.

20 Bernardo Bátiz Vázquez, Principio de información, en Teoría del derecho parlamentario, México: Oxford University Press, 1999, pp.117-123. 


\subsection{La biblioteca en la estructura política de la Jefatura del Estado}

En primera instancia es necesario entender el concepto político «Jefatura del Estado». Aragón ${ }^{21}$ al respecto asevera que a ésta "le corresponde ostentar la suprema representación del aparato institucional". Desde esta perspectiva, la magnitud política del jefe del Estado, que parte de la titularidad del ejecutivo en el sistema presidencial, está en relación con las funciones políticas del Estado; es decir, con la intensidad del poder estatal reflejado en las facultades que le confiere la Constitución en relación con la toma ejecutiva de decisiones políticas fundamentales, manifestación superior que constituye el conjunto de actividades a través de las cuales se refleja el poder del Estado. Recordemos que la Constitución es la Ley política suprema que norma la estructura y organización del Estado, incluida, por supuesto, la función pública del jefe del Estado encarnado en el Presidente de la República.

$\mathrm{McKay}^{22}$ en torno de este personaje afirma que "es el comandante-en-jefe, el jefe ejecutivo (y el principal diplomático), empleado de gobierno y servidor público, líder y miembro de un partido político, ciudadano y miembro de familia”. De acuerdo con esto ¿qué se entiende que sea un Jefe de Estado? Es la persona que representa a un país en el concierto de la serie de pueblos constituidos en Estados alrededor del mundo; es el personaje político que participa, directamente o mediante delegados diplomáticos, en reuniones de carácter de política internacional; es, en suma, quien personifica y representa a la Nación a través de las acciones y las decisiones estatales que configuran la función gubernamental del poder del Estado en la esfera inherente a temas o asuntos internacionales de diversa índole.

Pero el terreno de las acciones políticas de la Jefatura del Estado referente al sistema presidencial ¿se da sólo entre Estados? ¿acaso en el nivel nacional no tiene presencia esta identidad política? Al distinguir, por ejemplo, en el plano nacional las políticas públicas de Estado de las políticas públicas de gobierno, es factible inferir que la Jefatura del Estado, en el entramado de la estructura institucional del Estado, también tiene una importante dimensión nacional en cuanto a ejercicio político se refiere. De esta manera la concepción del término que nos ocupa se asocia tanto a temas internacionales como nacionales. Empero, para efectos de diferenciar claramente la Jefatura de Estado de la Jefatura de Gobierno, ilustraremos solamente la capacidad internacional de representación exterior de la noción política denominada

21 Manuel Aragón, «Gobierno y administración», en Filosofía política II. Teoría del Estado, Madrid: Editorial Trotta, 1996, pp. 83-94.

22 Pamela R. McKay, "Presidential papers: a property issue", en Library Quarterly. 52 (1), (January 1982): 21-40. 
como jefe del Estado, para argumentar la importancia y justificar la necesidad de contar con un sistema de información documental en cuyo esquema informativo se incluya la biblioteca presidencial, considerando la tendencia contemporánea que se asocia a la categoría de biblioteca digital.

Si la clave del éxito de un jefe de Estado en materia de relaciones exteriores es saber dominar el ejercicio político de algunos verbos, tales como saber, conocer, informar, negociar y representar, entonces el Órgano de Poder Ejecutivo, investido de competencia y autoridad, debe incluir en su estructura el servicio de biblioteca presidencial, con los recursos impresos y electrónicos necesarios para poder asistir eficazmente a dicho funcionario público y a su grupo de colaboradores que conforman ese órgano. En efecto, los diversos temas de interés nacional planteados mediante misiones en el exterior, requieren, por una parte, de una base sólida de conocimiento e información y, por la otra, de una plataforma de negociación y representación. De lo que se trata, entonces, no es de crear una biblioteca presidencial personal al modo estadounidense, sino una biblioteca presidencial institucional. Desde luego que el presidente en turno tiene el derecho, e incluso el deber, de formar su biblioteca personal, pero ésta no debe ser sustituida por la de carácter institucional, la cual, independientemente del cambio periódico del personal de la Presidencia de la República, deberá continuar su desarrollo para el apoyo de los futuros jefes de Estado y de Gobierno.

En concordancia con lo anterior el radio de acción de la biblioteca presidencial personal se limita al titular del Órgano de Poder Ejecutivo, o sea, al Presidente de la República; mientras que se espera que la biblioteca presidencial institucional extienda su área de apoyo a la acción política de todo el Órgano del Poder Ejecutivo; esto es, sus servicios bibliotecarios deben apuntar a asistir tanto al presidente como al staff de las diversas Direcciones y Oficinas de la Presidencia de la República; así como, en caso necesario, a su gabinete o consejo de ministros o secretarios. No obstante, la existencia de la biblioteca presidencial institucional en el seno del Órgano del Poder Ejecutivo, no deberá tener la pretensión de sustituir a las bibliotecas gubernamentales que todas las secretarías de Estado tienen la necesidad de crear y desarrollar para desempeñar las funciones que les señalan la Constitución y legislación federales. En todo caso, se deberán estrechar lazos de cooperación entre ellas.

La diversidad de problemas que un Jefe de Estado tiene que resolver sugiere que el personal de toda biblioteca oficial, al servicio directo del aparato presidencial de la República, procurará desarrollar colecciones básicas y selectas, así como gestionar servicios bibliotecarios y de información de elevada calidad. En este sentido este tipo de centro bibliotecario debe ser una entidad 
de servicio bibliográfico-documental de información para: 1] auxiliar con información que demande el trabajo ejecutivo que lleva a cabo el presidente de la República; 2] apoyar los mecanismos de captación de datos concretos e información directa que requiera el personal de apoyo al Ejecutivo; y 3] servir de enlace con los servicios de otras bibliotecas gubernamentales, tales como las que existen en la estructura de la Administración Pública Federal.

La idea es que el servicio de biblioteca presidencial, con perspectiva de cooperación bibliotecaria, apunte a favorecer la formulación y la conducción de comunicación social y política que el Jefe de Estado necesita transmitir en o hacia el exterior. Así, el establecimiento de una biblioteca presidencial es indispensable para respaldar documentalmente los actos políticos que se relacionan, por ejemplo, con los temas complejos que se refieren a la integridad, la estabilidad y la permanencia del Estado. Dada la naturaleza de la Jefatura del Estado, la biblioteca oficial de apoyo a ésta tendrá que entrar en constante contacto con la biblioteca de la Secretaría o el Ministerio de Relaciones Exteriores, puesto que este organismo es comúnmente el responsable de promover la coordinación del trabajo diplomático y consular en el exterior, y apoyar al Jefe del Estado en la conducción de la política exterior.

Se precisa, entonces, que la biblioteca presidencial satisfaga las necesidades de información política, social, jurídica y económica que requiere la Jefatura del Estado, con el fin de favorecer la eficacia de acción del Órgano de la Presidencia de la República en materia de dirección política exterior. Así, el Jefe de Estado, en el desempeño de la diplomacia presidencial que le corresponde realizar, debe contar con servicios bibliotecarios que le ayuden a obtener información documental pertinente y oportuna para elaborar los documentos presidenciales que debe llevar consigo en los viajes o en las recepciones de jefes de Estado. Pero ¿qué entendemos por este término? $\mathrm{McKay}^{23}$ responde: “'documentos presidenciales' es un término paraguas para una diversidad de materiales, escritos y grabados. Los documentos reflejan los diversos roles desempeñados por un Presidente". En este caso los documentos que prepara la persona que representa el Poder Ejecutivo, en su calidad de jefe de Estado, son los que responden a su quehacer orientado por las relaciones que ejecuta en materia tanto de diplomacia presidencial bilateral como de diplomacia presidencial multilateral. El personal bibliotecario al servicio de una Jefatura del Estado no deberá perder de vista que las relaciones internacionales no sólo se establecen con los jefes de Estado, sino también con los secretarios generales de la Organización de la Naciones Unidas, de la Organización de Estados Americanos, con los jefes o los directores de organismos internacionales, tales como el 
Fondo Monetario Internacional, el Banco Mundial, el Banco Interamericano de Desarrollo, la Comunidad Económica Europea y otros organismos.

En esta tesitura los documentos presidenciales son los que al término del periodo del ejercicio presidencial de un determinado Jefe de Estado, pasan a formar parte importante, como es el caso de los Estados Unidos, de la biblioteca-archivo personal. Se trata de la biblioteca-archivo que es desarrollada y organizada principalmente con el acervo de documentos que emanan de la dinámica política del Ejecutivo Federal, producto del trabajo que el Presidente de la República aporta y que durante o después de su gestión dispone que se ofrezca al público. Esto es posible ilustrarlo con el caso de un ex presidente de México, Miguel de la Madrid Hurtado, quien en su obra, El ejercicio de las facultades presidenciales, apunta:

Concedí una gran importancia a documentar y a dejar organizadas las fuentes de información sobre la acción gubernamental. Para ello creé, dentro de la Presidencia de la República, un Centro de Documentación y Crónica Presidencial con servicio al público a fin de poner a su disposición los principales informes, estudios y documentos de la gestión gubernamental. Este acervo, sistematizado, ordenado y clasificado, fue entregado al Archivo General de la Nación en noviembre de $1988 .^{24}$

Considérese el término «centro de documentación» como sinónimo de «biblioteca». La variedad temática y la considerable cantidad de estos fondos documentales que un jefe de Estado produce en el transcurso de su actividad política presidencial, representan una carga extraordinaria de trabajo para las capacidades del personal calificado que se dedica a la organización de la variedad de colecciones.

La situación internacional hoy en día, a causa de la globalización, hace que las relaciones diplomáticas, bilaterales y multilaterales que lleva a cabo un Jefe de Estado se desarrollen en medio de un complejo esquema de altibajos y zigzags. El deseo de la paz y no de la guerra; la cooperación y no la confrontación; la democratización, el diálogo y la solidaridad en las relaciones internacionales y la no hegemonía ni el unilateralismo, son algunas de las aspiraciones e intereses que persigue toda Jefatura del Estado, particularmente los jefes de Estados no hegemónicos. En este sentido, parece prudente afirmar que un Presidente de la República sin sistemas y servicios de información documental adecuados a su alcance, en los que se incluya a

24 Miguel de la Madrid Hurtado, El ejercicio de las facultades presidenciales, México: Editorial Porrúa, Universidad Nacional Autónoma de México, 1999, p. 66. 
la biblioteca presidencial, hace prácticamente imposible mantener diálogos estratégicos de alto nivel en los cuadrantes de un mundo globalizado y, por ende, sería difícil alcanzar importantes consensos con otros jefes de Estado. El incremento de la comprensión mutua y la confianza entre ellos tienen una importancia capital para impulsar un mayor desarrollo de los lazos de amistad entre los pueblos.

Asuntos internacionales, tales como la cooperación económica y comercial; el combate al narcotráfico; la cooperación antiterrorista sobre la base de beneficio mutuo; el respeto de los derechos humanos de los diversos grupos sociales vulnerables; el intercambio científico, tecnológico y cultural; la salvaguarda de la soberanía de los Estados y la estabilidad de las diferentes regiones del mundo; y otros, denotan la necesidad perentoria de contar con modernos sistemas y servicios de información, con particular énfasis de los electrónicos, mismos que estén a disposición permanente de la Jefatura del Estado. Ianni, teórico brasileño del fenómeno de la globalización, sostiene que

[...] en el ámbito de la aldea global, prevalecen los medios electrónicos como un poderoso instrumento de comunicación, información, comprensión, explicación e imaginación de lo que sucede en el mundo. Junto con la comunicación impresa, los medios electrónicos pasan a desempeñar el singular papel de intelectual orgánico de los centros mundiales de poder, de los grupos dirigentes de las clases dominantes. ${ }^{25}$

Entre estos últimos podemos incluir a los líderes que representan el Poder Ejecutivo de los Estados de Derecho. No olvidemos que la política exterior se forma bajo la influencia de factores objetivos, entre los que podemos mencionar la situación geográfica del país y sus características sociales, históricas, económicas, culturales e ideológicas. En este orden de ideas, los servicios de información documental deben ayudar a la Jefatura del Estado a comprender todo ese entorno para lograr, en la medida de lo posible la práctica de una diplomacia basada en valores cívicos y éticos, en lugar de una diplomacia respaldada en la fuerza militar o en la carga o sanción económica.

No ha sido nuestro propósito adentrarnos en la documentación que produce el jefe del Estado, sin embargo, es posible advertir que la naturaleza de los documentos presidenciales asociada con su cargo, proporciona orientación sobre la importancia que debe tener el servicio de biblioteca presidencial 
en la mira tanto de los políticos como del personal profesional de la bibliotecología. De este modo la literatura en torno de esta disciplina debería poner tanta o más atención, como lo ha hecho en relación con el servicio de biblioteca parlamentaria, en la información como objeto de estudio y análisis, pues en el marco teórico y práctico del Estado de Derecho, esta información organizada en los sistemas bibliotecarios pertenecientes a los poderes Legislativo y Ejecutivo representa, en uno y otro, un recurso sustancial de contrapeso para evitar la concentración omnímoda del poder público.

El interés por la biblioteca presidencial en activo (es decir, los servicios de información a través del centro bibliotecario de este género durante la gestión política del principal mandatario de un Estado) reside, desde otra óptica, en que las actividades del jefe del Estado se extienden sobre una gama muy amplia de asuntos públicos en materia de política exterior; además de que apuntan, en periodos de crisis internacionales, hacia una mayor expansión en todas las esferas principales que configuran los actos de la diplomacia presidencial. En esta tesitura, si el liderazgo del órgano del Poder Legislativo reconoce explícitamente la necesidad de los servicios bibliotecarios y de información parlamentarios para cumplir con su labor política, el Poder Ejecutivo no puede sino aceptar también ese reconocimiento que le corresponde en el plano de su competencia, por ende, no puede carecer de un servicio de biblioteca, suficiente y eficiente, dentro de la estructura de la Presidencia de la República.

\subsection{La biblioteca en la estructura política de la Jefatura del Gobierno}

Como hemos dicho, y asegura también el escrito citado de Aragón, ${ }^{26}$ la Jefatura de Gobierno es la otra entidad política en la estructura gubernamental que conocemos como sistema presidencial. La Jefatura del Gobierno es en sí la cabeza del Poder Ejecutivo, es la que desempeña la función gubernativa y, por ende, la que realiza el poder de gobernar a un Estado desde la Presidencia de la República, o sea, es el órgano que tiene el poder para dirigir la política interior del Estado. Así, la teoría del Estado estudia y analiza el concepto de Gobierno como fuente de poder político y como función política de la superestructura estatal. Considerado como órgano director de la política de un país, ese elemento del Estado está estructurado de forma compleja.

Para hacer efectivo ese poder y cumplir con esa función, el Gobierno tiene un conjunto organizado de órganos llamados, según el país, Ministerios, Secretarías o Departamentos. Ese conjunto de instituciones es la estructura 
denominada Administración Pública Federal, sistema que actúa como el brazo derecho de la Jefatura del Gobierno. González ${ }^{27}$ al referirse a las estructuras del poder político, asevera que "el Presidente de la República es el que encabeza, con plenos poderes, la Administración Pública”. De tal suerte, en el presente rubro nuestro enfoque se circunscribe a la Jefatura del Gobierno del Poder Ejecutivo, sin adentrarnos en la teoría de las instituciones bibliotecarias que están al servicio de las secretarías o ministerios de Estado.

En efecto, intentar dilucidar en el rubro anterior acerca de la biblioteca presidencial al servicio de la Jefatura del Estado, significó adentrarse en la noción de un género de biblioteca que está incrustada en el poder político del Estado. Ahora se trata de reflexionar en torno de un momento concreto de la biblioteca como servicio de organización y prestación de información documental en apoyo al quehacer que realiza quien tiene a cargo la Jefatura del Gobierno. Como sucede en la esfera de la diplomacia presidencial, en virtud de la importancia que tiene la dirección gubernamental administrada por ese órgano, resulta preciso reconocer la necesidad que se tiene en este rubro en materia de servicios, directos y eficaces, de biblioteca. No se trata, por supuesto, de formar un recinto de esta naturaleza para cada una de las dos entidades políticas que constituyen la forma presidencial de gobierno, sino de distinguir la necesidad política de contar con una biblioteca presidencial para asistir, paralelamente, tanto a la Jefatura del Estado como a la Jefatura del Gobierno, binomio institucional y constitucional en el que se estructura la Presidencia de la República. Órgano de Poder Federal sobre el que recae la responsabilidad política de cumplir las funciones ejecutivas y administrativas que le conciernen al gobierno presidencial. Una de las modalidades del gobierno republicano.

Serra ${ }^{28}$ afirma que "la eficacia de un Gobierno se mide no por lo que dice, sino por lo que hace con eficacia". Esto es relativamente cierto, pues subestimar el peso que tiene la palabra de lo que se hace con eficiencia en el mundo político, característico al Poder Ejecutivo, sería minimizar la carga política que tienen, por ejemplo, los discursos orales y escritos que a menudo pronuncian por mandato superior los voceros del Presidente de la República o el presidente mismo en su condición de jefe gubernamental. En torno de esto no perdamos de vista que la Constitución le concede al Presidente de la República, en el marco del régimen presidencial, deberes de naturaleza pública inherentes a un jefe de Gobierno. De ahí que Eshbaugh-Soha ${ }^{29}$ asegure que "las actividades públicas del presidente son de importancia teórica substancial”,

27 Héctor González Uribe, Teoría política, México: Editorial Porrúa, 1995, p. 401.

28 Andrés Serra Rojas, Teoría del Estado, México: Editorial Porrúa, 1998, p. 87.

29 Matthew Eshbaugh-Soha, "Presidential press conferences over time", en American Journal of Poliitical Science, 47 (2), (April 2003): 348-353. 
entre ellas las conferencias presidenciales de prensa, pues este autor considera que

[...] las ruedas de prensa son uno de los vehículos más importantes en los cuales los presidentes comunican a los medios y al público. La evidencia cualitativa y el saber convencional mantienen que el uso de la rueda de prensa es una función de los presidentes.

En relación con esto, el deber de informar a la prensa sugiere que quien asuma la responsabilidad de la Jefatura del Gobierno, debe contar con un sistema de información documental de elevada calidad para poder, a su vez, informarles, en tiempo y forma, a los medios masivos de comunicación, quienes, a su vez, tienen la responsabilidad social de informarle a la sociedad sobre el quehacer de este funcionario público.

Hablar frente a una serie de reporteros nacionales e internacionales sobre temas candentes de política, sociedad, economía, ciencia, tecnología, derechos humanos, defensa, seguridad, empleo, vivienda, salud, desastres naturales, soberanía, etcétera, exige que la Jefatura de Gobierno cuente con capacidad de expresión elocuente y conocimiento concreto; por ende, con recursos suficientes y eficientes de información gubernamental, entre ellos el servicio de biblioteca presidencial, que le permitan usar un lenguaje y conocimientos acordes con el nivel ejecutivo que sustenta. El mal uso del lenguaje, evidenciado a través de los traspiés declarativos de un jefe del Ejecutivo, presenta el riesgo de degradar la investidura presidencial y, por ende, exponerla a un desprestigio que puede originar confrontaciones institucionales, e incluso problemas internacionales. Un discurso presidencial debe estar elaborado con información veraz y conocimiento pleno del problema, no en ocurrencias que vulneren esa figura de poder gubernamental. Los errores políticos, sociales, geográficos, históricos y literarios, entre otros, podrían evitarse con la práctica cotidiana y sistemática de la lectura y el uso asiduo de la biblioteca presidencial, tanto por parte de quienes elaboran los discursos presidenciales como de quien los aprueba, lee y pronuncia de cara a la nación. Desde esta óptica, ese centro bibliotecario no puede ser, en la teoría y en la práctica, un asunto pendiente o asignatura inexistente.

En el caso de las conferencias de prensa, convertidas en documentos presidenciales audiovisuales, tales como grabaciones en video y fotografías, éstos podrían pasar a formar parte importante de las colecciones de ese tipo de centros bibliotecarios. Respecto a este tipo de documentos, $\operatorname{Cox}^{30}$ advierte

30 Richard J. Cox, "America's pyramids: presidents and their libraries", en Government Information Quarterly, 19 (2002): 45-75. 
que en 2002 las diez bibliotecas presidenciales estadounidenses (Bush, Carter, Eisenhower, Ford, Hoover, Johnson, Kennedy, Reagan, Roosevelt, Truman), además del acervo documental del presidente Nixon, contenían más de 7 millones de fotografías, 14.5 millones de pies de película, 83.000 horas de disco, cinta magnética para audio y grabaciones en videocinta. Cifras que debieron aumentar considerablemente con la William J. Clinton Presidential Library, ${ }^{31}$ inaugurada en noviembre de 2004 por el presidente George W. Bush.

De tal modo que si reconocemos que la información documental, incluida la audiovisual, es sumamente necesaria para los diversos quehaceres de gobierno que entrañan los actos de comunicar e informar, entonces la biblioteca presidencial en activo tiene el deber de organizar y proporcionar una gran gama de información que demanda el trabajo político del órgano en cuestión. Ciertamente los periódicos, la radio, la televisión, la Internet y otros medios informativos ofrecen gran cantidad de informaciones, pero la cantidad y la diversidad de puntos de vista que se vierten sobre una determinada temática hacen necesario que ese tipo de biblioteca desarrolle, por un lado, los procesos de compilación, selección y organización de ese recurso que se asocia con el poder político y, por el otro, que entre sus fuentes documentales incluya, por supuesto, las que ofrecen los medios impresos y electrónicos. En el plano de la información política del Poder Ejecutivo, el Gobierno republicano y poder dominante es el enlace que el profesional de la bibliotecología puede relacionar con la unidad documento presidencial y biblioteca presidencial.

Hacer referencia al papel que juega el centro bibliotecario que sirve a la Jefatura del Gobierno significa desarrollar, organizar y difundir colecciones bibliográficas y/o documentales con base en las políticas gubernamentales de la nación, las cuales deben ayudar a solucionar los problemas que enfrenta la ciudadanía. En este sentido, los ejes de funcionamiento de los servicios bibliotecarios presidenciales giran alrededor del concepto de «políticas públicas», en las que se combinan y complementan políticas de Estado y políticas de Gobierno. La línea divisoria que hemos hecho en el presente discurso entre la Jefatura del Estado y la Jefatura del Gobierno es una perspectiva que nos puede ayudar a diferenciar entre unas y otras. Sin embargo, en la vida interna de un Estado se planifican y realizan ambos tipos de políticas públicas; esto es, de Estado y Gobierno.

La esfera de nuestro fenómeno de análisis nos permite afirmar que las bibliotecas presidenciales, en plena práctica para asistir al jefe de Gobierno, 
deberán contemplar como uno de sus objetivos el apoyar, a través de sus colecciones bibliográficas y servicios bibliotecarios de información documental, las políticas públicas presidenciales. Se trata de la esfera que corresponde a los programas de acción de la autoridad pública que encabeza el Poder Ejecutivo. Esto revela, en general, que una política pública es la decisión gubernamental que configura la solución de un problema determinado de la sociedad; y, en particular, que una política pública presidencial es una decisión originada en la Jefatura de Gobierno con el fin también de solucionar un problema que aqueja a la comunidad.

Así, los servicios bibliotecarios destinados a servir al Presidente de la República deberán diseñar diversas modalidades de acceso a la información, y también pensar y aplicar mecanismos que favorezcan a la comunidad de usuarios gubernamentales que asisten a esa Jefatura, incluyendo a su titular. Lahera al relacionar políticas públicas e información se aproxima a nuestra idea, pues dada la circulación de la información en materia de políticas públicas, indica que

[...] una condición necesaria para que el Estado tenga éxito en las tareas que se le encomiendan es la que éste disponga de una adecuada informatización de procesos, de interconexión vía redes y de acceso a bases de datos dispersas por el mundo con información necesaria para el desarrollo. ${ }^{32}$

Siguiendo en esta línea, las instituciones bibliotecarias, en el contexto que nos ocupa, deberán auxiliar con información completa, veraz y oportuna los pasos que implica la elaboración de políticas públicas; esto es, de acuerdo con Ruiz, ${ }^{33}$ en la: 1] identificación y definición de los problemas; 2] percepción de la problemática actual y futura, 3] selección de soluciones, 4] establecimiento de objetivos o metas, 5] selección de los medios, y 6] implementación.

Desde esta perspectiva, si la Jefatura del Gobierno es el órgano que dirige la realización de las políticas públicas de un país, entonces el objetivo principal del Gobierno es alcanzar resultados positivos en cuanto a bienestar social se refiere. Con base en estas ideas, a la biblioteca presidencial se la puede concebir como un sistema de información documental organizada y como un instrumento de enlace con otras bibliotecas gubernamentales para lograr ese objetivo. Las facultades inherentes a la dirección política de la nación, que se

32 Eugenio Lahera Parada, Introducción a las políticas públicas, México: Fondo de Cultura Económica, 2002, p. 221.

33 Carlos Ruiz Sánchez, Manual para la elaboración de políticas públicas, México: Plaza y Valdés, 1996, p. 15. 
le atribuyen a la Jefatura de Gobierno como componente central del Poder Ejecutivo, son tan importantes como las funciones y actividades que realizan las cámaras del poder Legislativo.

\section{LA Biblioteca Al SERVicio Del titular DE LA PRESIDENCIA DE LA REPÚBLICA}

En los rubros anteriores se ha tratado, desde una óptica general, la relación biblioteca presidencial y Presidencia de la República, dividiendo nuestro análisis en relación con los dos órganos que constituyen a esta última: la Jefatura del Estado y la Jefatura de Gobierno. Ahora dediquemos el presente apartado a reflexionar acerca del nexo biblioteca presidencial y Presidente de la República; esto es, en torno del servicio de biblioteca de este género para asistir, en concreto, al titular del Poder Ejecutivo. Para tal efecto se intenta exponer dos dimensiones de razonamiento: 1] en la dinámica de sus actos políticos y 2] en el desarrollo de sus facultades y obligaciones constitucionales, en ambos casos como presidente de la República.

\subsection{La biblioteca en la dinámica de los actos políticos presidenciales}

El propósito de las bibliotecas presidenciales, a juicio de Brooks, ${ }^{34}$ "es preservar y hacer disponible en un lugar todos los materiales de una Administración Presidencial". La función de preservación en relación con este tipo de centros, es la principal directriz que se esgrime en el plano del ejercicio bibliotecario presidencial en los Estados Unidos. Esa función se asocia al concepto biblioteca-archivo; mientras que la idea de hacer disponible los documentos presidenciales se articula con el concepto de biblioteca de investigación, expresión que se relaciona con la función de servicio que se pretende que esas bibliotecas realicen a partir de su apertura al público. Pero la disponibilidad de algunos acervos está acotada en virtud de la contención o prohibición que existe, por orden ejecutiva, de no prestar la información clasificada bajo el rubro de seguridad nacional.

Como se puede colegir, la perspectiva bibliotecológica estadounidense tampoco nos permite dilucidar el funcionamiento de la biblioteca presidencial durante la dinámica de los actos políticos del Presidente de la República, los cuales son la parte esencial que nos puede ayudar a seguir construyendo

34 Philip C. Brooks, "A special library for the presidency", en Missouri Library Association Quarterly, 23 (June 1962): 42. 
la base argumentativa para sostener la propuesta sobre la necesidad de que todo primer mandatario de una nación en un régimen presidencial, gobierne eficazmente con servicios bibliotecarios y de información a su alcance inmediato.

Si la biblioteca presidencial debe ser un apoyo sustancial en la dinámica de los actos políticos del titular de la Presidencia de la República, es menester preguntar ¿qué se entiende por actos políticos? Serra nos ayuda a responder al aseverar que:

La política es una actividad encaminada a la constitución, desarrollo y funcionamiento del poder público. Ella origina la doble relación gobernantes y gobernados, es un proceso de mando y obediencia. Esta actividad o acción política se traduce en la realización de actos y bechos políticos, y los actos materiales que se relacionan con los mismos. Toda actividad debe estar vinculada al ejercicio del poder. ${ }^{35}$

Desde este escorzo, los servicios bibliotecarios presidenciales están encaminados a favorecer, en efecto, el trabajo político de quien tiene el poder político-ejecutivo del Estado, o sea, el mandato de gobernar a través de la titularidad del Poder Ejecutivo Federal. Estamos ante el actuar político del funcionario público que ejerce el poder como jefe de Estado y de Gobierno. $\mathrm{Y}$ actuar políticamente en ese nivel significa reconocer la necesidad de hacer uso, sistemático e intenso, de las diversas fuentes de información que la biblioteca presidencial le ofrezca al primer mandatario de la nación, con el fin de que él pueda estar informado y así le sea factible analizar, deliberar, disponer y decidir, pues como dice Fayt, "36 "la decisión es la culminación de la acción activa de la política". Así las cosas, la biblioteca destinada a asistir al presidente es una forma definida y concreta de servicio bibliotecario y de información que se distingue de otras formas de bibliotecas gubernamentales que se ubican dentro del marco de estudio del Estado de Derecho.

En este plano de reflexión nuestra idea de biblioteca presidencial alejada del modelo estadounidense, que ha sido analizado en un rubro anterior, tiene acotado su campo de acción, por lo que sus principios deben analizarse a luz de los principios del quehacer bibliotecario gubernamental, algunos de los cuales son mencionados por Neut. ${ }^{37}$ Desde esta perspectiva el tipo de biblioteca que nos ocupa es, en el más claro sentido, el recinto documental necesario que responde a la función política de uno de los poderes que configuran al Estado. La consistencia teórica de la biblioteca presidencial en activo

35 Andrés Serra Rojas, Op. Cit., pp. 86-87.

36 Carlos S. Fayt, Teoría de la política, Buenos Aires: Editorial Perrot, 1960. p. 68.

37 Hans van der Neut, op. cit. p. 261. 
está vinculada, pues, con la realidad política y, por ende, con los mecanismos de la acción del poder público presidido por el Titular del Ejecutivo Federal.

Que la biblioteca presidencial se vuelva una necesidad perentoria, durante el pensar y hacer de un presidente, en todos los Estados democráticos de Derecho, parece un tema extravagante para la teoría bibliotecológica que intenta trazar la cultura de las «necesidades de información» de la sociedad organizada en ese tipo de formación político-social. Una muestra es la ausencia explícita de este tipo de centro bibliotecario, no así la ausencia de éste en la estructura del Poder Ejecutivo. Y todavía más extravagante parece la posibilidad de que, sin esa teoría, pueda ser cuestionada la satisfacción de las necesidades políticas de información o las necesidades de información política de un presidente de la República. De acuerdo con la literatura bibliotecológica, se tiene la sospecha de que para el bibliotecólogo no existe o no tiene importancia para él ese usuario potencial de información bibliográfica, pues esto sólo se evidencia cuando, como en el caso de los Estados Unidos, el presidente termina su cargo público y convierte la masa documental que acumuló a lo largo de su administración en una biblioteca presidencial, que ofrece documentos para el interés más del historiador que del político y del politólogo; para mostrar más el lujo de quien gobernó los destinos de la nación más poderosa del Occidente que la función de servicio de esas bibliotecas-museo para el pueblo estadounidense.

Una clara evidencia acerca de esto es la obra de Smith ${ }^{38}$ intitulada Windows on the White House: the story of presidential libraries. Por lo que en atención a la naturaleza del fenómeno de esa biblioteca en el contexto estadounidense, la expresión más correcta para denominarla sería biblioteca ex presidencial, momento intelectual del quehacer bibliotecario de esa nación que se ha acogido a una suerte histórico-teórica que evidencia tanto la voluntad de decisión política como de privilegio político para la construcción de lujosos edificios de bibliotecas que alberguen la herencia documental derivada del ejercicio ejecutivo de algunos ex presidentes. Es necesario rebasar esta visión de biblioteca presidencial que tiende a convertirse en una versión acotada, puesto que no hace más que restringir el problema e impedir así reflexionar alrededor del nexo conformado por el elemento-objeto (biblioteca presidencial) y el elemento-sujeto (presidente de la República), ambos en los cuadrantes de la práctica de la política llevada a cabo por el actor político que encabeza el Poder Ejecutivo. 
La relación información, biblioteca y presidente debiera girar en torno de una adecuada confección de decisiones ejecutivas, las cuales, como observamos cotidianamente, están expuestas a las presiones de los líderes legislativos, los dirigentes de los partidos políticos, los integrantes de diversos grupos de interés, las ideologías de carácter internacional y nacional, los repre sentantes de otros Estados, etcétera. Por lo que el servicio de biblioteca presidencial debe apoyar la eficacia de la estructura política presidencial que tiende a estabilizar gran parte de la actividad del gobierno hoy en día. Los actos del presidente, reflejados en la toma de decisiones políticas, requieren de una plataforma de servicios bibliotecarios y de información eficaces. La composición del ambiente en el que el presidente de la República se desenvuelve, sugiere que él no es un sujeto pasivo en la elaboración de noticias, pues su poder reside en gran medida en el uso y la administración de la información con la finalidad de generar material destinado tanto para la prensa gubernamental como para la prensa no gubernamental, nacional e internacional.

Por lo tanto la rueda de prensa, en virtud de la necesidad de información que requiere, amerita particular atención por parte de la biblioteca dedicada a asistir a dicho funcionario público. De tal suerte que en virtud de esa necesidad de información política que demanda el discurso introductorio y la ronda de preguntas/respuestas durante una conferencia de prensa, ésta puede ser un eslabón entre el titular de la Presidencia y la biblioteca a su servicio, por lo que en el plano de esta actividad presidencial el centro bibliotecario se podría convertir en un centro de información que refuerce el manejo de asuntos que caracterizan todo acto político del buen gobernar a partir de las facultades constitucionales que se le confieren al presidente de la República. La diferencia de contar o no con servicio efectivo de biblioteca en este contexto político puede distinguir entre la figura de un presidente informado o un presidente desinformado. Diferencia que traza, incluso, una línea divisoria entre un presidente culto o inculto.

Desde otra arista, la legitimidad de la biblioteca presidencial en el actuar político del titular del Poder Ejecutivo debe ser reconocida bajo el perfil de su eficacia para brindar, sistemáticamente, la información documental que requiere la acción creadora que conlleva tal cargo público, acción que ha de apuntar hacia la esperanza de configurar una nación mejor, un Estado mejor gobernado. En esta perspectiva, tal centro bibliotecario no se puede reducir a un mero depósito organizacional de documentos presidenciales y dedicarse sólo al desempeño de la función de preservación organizada de los mismos, pues de ser así se estaría actuando para formar más bien una biblioteca postpresidencial, tal como ha venido suscitándose en el terreno estadounidense. 
Menez, ${ }^{39}$ en este contexto, asevera: "Las bibliotecas presidenciales consolidan el orgullo y elevan el tono de una comunidad de la misma manera que lo hacen las universidades".

Si aceptamos esta idea, entonces el centro bibliotecario para apoyar los hechos políticos del presidente debería ser contemplado en todo el mundo con la misma atención que se le ha venido dando a las bibliotecas universitarias o académicas. Pero como no es así, la biblioteca presidencial en activo debe considerarse como un producto de la cultura del poder político, una institución que contribuye a documentar los actos políticos del ejecutivo, que revelan las diversas direcciones y propósitos de la vida política en acción del Ejecutivo. Perfilar la tendencia de la relación bibliotecas presidenciales y actos políticos es reconocer la importancia y la necesidad de poseer los medios de información bibliográfico-documental para todos aquellos actos, cualesquiera que sean, que emanan de la autoridad presidencial y se cumplen en forma ejecutiva.

Si bien el titular de la Presidencia de la República tiene un determinado campo de acción en el marco de la distribución de los poderes públicos, es también cierto que este funcionario público adquiere un amplio poder de acción vinculado con los diversos actos políticos que realiza, de los cuales emerge la amplia gama de necesidades de información, que a la vez pueden y deben determinar el radio de actividad respecto a la planeación, la creación, el desarrollo, la organización y el funcionamiento de los servicios bibliotecarios presidenciales. Desde esta óptica se observa que el poder político del presidente se revela mediante los actos políticos que efectúa. Y tanto el poder como los actos es factible asociarlos con la actividad bibliotecaria destinada a favorecer a ese ciudadano electo democráticamente como primer mandatario.

La importante consecuencia que se desprende de esta visión teórica es saber cuál es el objeto de la función social de la biblioteca presidencial en activo. Pues como hemos analizado, la teoría de la biblioteca presidencial estadounidense que podría construirse con base en la literatura disponible, por lógicas que fuesen sus deducciones, tendría el defecto de no haber sino sido hecha para determinadas coordenadas de tiempo y espacio, y por ende estaría desprovista de fundamento no sólo para otros regímenes republicanos sino para el estadounidense mismo, en tanto que, como se ha puntualizado, se trata más bien de centros bibliotecarios con fondos bibliográficos y documentales de ex presidentes, disponibles para asistir al historiador y a las ter 1972):34-39. 
personas que tienen alguna curiosidad sobre la vida de un personaje que ha representado el Poder Ejecutivo de los Estados Unidos.

Entonces, en sentido riguroso, la actividad bibliotecaria en el ámbito del presidente de la República debe girar en derredor de los actos políticos que el poder, dentro de los límites fijados por la ley, le permite realizar a esa autoridad. Desde esta perspectiva y tomando como base el documento de Relyea, ${ }^{40}$ el sistema bibliotecario presidencial Federal de ese país debería hacer explícitos sus servicios tanto para la comunidad estadounidense como, y principalmente, para el titular de la Presidencia de la República en su plena función ejecutiva, pues Veit ${ }^{41}$ en su obra Presidential libraries and collections - a nuestro juicio la más completa sobre el tema- hace particular énfasis sobre los aspectos históricos, el trabajo de archivo, las características de las colecciones, los costos de construcción y mantenimiento de los edificios, las descripciones individuales de las mismas, y otros, pero menciona muy superficialmente el problema del acceso a los documentos presidenciales; por tanto, no se expresa el asunto relevante de los servicios bibliotecarios al público.

Esta situación nos permite comprender mejor por qué Cochrane ${ }^{42}$ intitula su artículo: «Presidential, yes; libraries, not really». Pensamos que no es este tipo de biblioteca presidencial (biblioteca-archivo-museo) lo que un titular de la Presidencia de la República requiere para el cumplimiento de sus actividades políticas durante su periodo de gobierno. Tengamos en cuenta que la acción política del Poder Ejecutivo no es menos importante que la acción política del Poder Legislativo en un Estado de Derecho, por lo cual es necesario que ambos poderes tengan instalado, en sus respectivos entramados orgánicos, los adecuados recintos bibliotecarios. Así, en su aspecto fundamental, la biblioteca presidencial puede definirse como la institución que asiste y provee de información a la autoridad que ejerce el Poder Ejecutivo dual, o sea, al titular del órgano ejecutivo constitucional que desempeña conjuntamente el cargo de Jefe del Estado y Jefe de Gobierno en la estructura de un régimen presidencial.

\subsection{La biblioteca en la práctica de las facultades y obligaciones presidenciales}

Con el propósito de continuar planteando el contorno de la biblioteca presidencial como un mecanismo de información inmediatamente eficaz para auxiliar al titular de la Presidencia de la República, es menester analizar ahora la influencia que ese tipo de servicio tiene o puede tener en el marco de las

40 Harold C. Relyea, “The Federal Presidential Library System”, Government Information Quarterly, 11 (1), 1994, pp.7-21.

41 Fritz Veit, op. cit. 152 p.

42 Lynn Scout Cochrane, op. cit. p. 59. 
atribuciones que la Constitución y leyes conexas le confieren al ejecutivo, las cuales reflejan tanto la posición política de ese cargo público en la estructura de la organización estatal como la función de liderazgo superior de quien tiene la responsabilidad de la dirección política del país. Desde esta arista, Carré advierte:

El Presidente de la República tiene directamente de la Constitución cierto número de poderes, como el de dirigir los asuntos exteriores, convocar a las Cámaras, etcétera, poderes cuya importancia es desde luego considerable y que ejerce, no ya a consecuencia y en virtud de leyes que emanan del cuerpo legislativo, sino fundado en su propia competencia constitucional. ${ }^{43}$

De acuerdo con esto, afirmamos que la biblioteca presidencial se ubica, teóricamente, en un estadio gubernamental superior, pues ella debe existir para apoyar la actividad del Estado que se realiza a través del órgano Ejecutivo. Recordemos que el presidente tiene, en la esfera del sistema federal, el papel dual de jefe de Estado y jefe de Gobierno, así que las facultades que este funcionario ejerce en un régimen de Derecho son aquellas que, en efecto, están expresamente relacionadas con el cargo de esas dos Jefaturas. Por lo tanto un análisis grosso modo de las facultades del presidente puede proveer el contexto necesario para entender, desde otro lugar, el peso específico que tiene o debería tener ese centro bibliotecario. Así, el alcance de la dicha biblioteca se puede determinar también por la trascendencia de las atribuciones y las funciones gubernamentales; es decir, por la actividad del Estado en cuanto a contenido y forma.

En atención a lo que expresa la Ley suprema de los regímenes presidenciales, Galindo ${ }^{44}$ advierte que "a la actividad del Estado se le ha dado diferentes nombres, tales como: prerrogativas, cometidos, derechos, facultades, servicios públicos, competencia, funciones y atribuciones, entre los más comunes". Así que para avanzar en nuestras reflexiones tomamos a la Constitución Política de los Estados Unidos Mexicanos como el molde político-documental principal, por lo que se usará la fórmula: «las facultades y obligaciones del Presidente» que se asientan en el Artículo 89 constitucional, sin menoscabo de otras expresiones válidas que hubiere en constituciones de otros países para argumentar el valor y la eficacia de la biblioteca presidencial en el derrotero que sigue el «ejecutivo dual» al encabezar el poder público de la actividad del Estado. 
Para entender mejor el nexo que es factible establecer entre biblioteca y presidencia en el contexto del supremo Poder Ejecutivo de la Federación, tengamos en mente las siguientes apreciaciones de Villa: ${ }^{45}$ 1] la institución presidencial pertenece al género de las grandes organizaciones de la política contemporánea, 2] en consecuencia, es la expresión de un orden social y político y de una unidad cultural, susceptibles de mayor vastedad y complejidad, y 3] es, en suma, una institución socialmente sólida, históricamente legítima, genéticamente democrática y orgánicamente perfectible. Por esto podemos ubicar a la biblioteca presidencial en el cuadrante institucional de la política estatal, destinada a procurar la satisfacción de las necesidades de información que el titular de la Presidencia de la República presenta con base en lo que le encomienda la Constitución y leyes conexas. De tal modo que una teoría de la biblioteca presidencial significa la elaboración de una teoría política de este género de organismo gubernamental, pues ella debe dedicarse a desarrollar y organizar las colecciones documentales pertinentes y a ofrecer una gama de servicios que logren ayudar a reforzar la toma de decisiones político-presidenciales, en aras de perfeccionar un trabajo ejecutivo que apunte a favorecer tanto el interés público como el interés nacional.

Ejemplifiquemos. Las facultades del presidente referentes al interés público en materia de asuntos internos se expresan en la Ley suprema mexicana esencialmente en la fracción I del Artículo 89: "Promulgar y ejecutar las leyes que expida el Congreso de la Unión, proveyendo en la esfera administrativa a su exacta observancia"; y sobre el mismo tenor pero en relación con el interés nacional respecto a las relaciones internacionales queda manifiesto en la fracción $\mathrm{X}$ de ese mismo artículo:

Dirigir la política exterior y celebrar tratados internacionales sometiéndolos a la aprobación del Senado. En la conducción de tal política, el titular del Poder Ejecutivo observará los siguientes principios normativos: la autodeterminación de los pueblos; la no intervención; la solución pacífica de controversias; la proscripción de la amenaza o el uso de la fuerza en las relaciones internacionales; la igualdad jurídica de los Estados; la cooperación internacional para el desarrollo; y la lucha por la paz y la seguridad internacionales. ${ }^{46}$

45 Manuel Villa Aguilera, op. cit., pp. 13-15.

46 México [Leyes]. Constitución Política de los Estados Unidos Mexicanos, texto vigente, última reforma publicada en el DOF 27 de septiembre de 2004, (citado 30 de mayo de 2005), disponible en Internet: http://www.cddhcu.gob.mx/leyinfo/doc/1.doc 
Recordemos la línea divisoria entre el jefe del Estado y el jefe del Gobierno. Sánchez ${ }^{47}$ la expresa de la siguiente manera:

el presidente de la República tiene la representación del Estado mexicano ante los organismos internacionales y frente a otros Estados [...] el presidente de la República desarrolla el gobierno de la Federación; sus atribuciones se significan en la aplicación en la esfera administrativa, de las normas de rango federal.

Por esta razón el interés nacional está asociado a las relaciones internacionales que el Jefe del Estado debe dirigir; y el interés público está vinculado con los asuntos internos de la nación que el Jefe del Gobierno debe conducir, y es tomando en cuenta estos dos ejes en los que giran las facultades de quien encarna el Poder Ejecutivo, alrededor de los cuales se debe basar y justificar la gestión bibliotecaria presidencial.

Como podemos inferir, la óptica normativa nos permite establecer explícitamente la raíz del nexo biblioteca presidencial y Estado de Derecho, pues al ser la Constitución la norma pública fundamental que da forma y estructura al Estado y, asimismo, al señalar las facultades y las obligaciones de los poderes públicos, entre ellos los del Poder Ejecutivo, se sugiere que ese centro bibliotecario sea reconocido como un mecanismo de apoyo documental extraordinario en el marco del Estado Constitucional, el cual es, en consecuencia, un Estado de Derecho. Estructura jurídico-política que, insistamos, requiere de servicios bibliotecarios presidenciales, además de los parlamentarios y jurídicos destinados a favorecer el trabajo de los otros poderes de la Federación. Servicios institucionales que forman importantes sistemas y subsistemas de bibliotecas gubernamentales en todo lo largo y ancho del aparato estatal, los cuales deben secundar la interacción entre esos poderes públicos, pues como observa Galindo, ${ }^{48}$ hoy en día no es posible concebir al órgano legislativo sólo legislando; al órgano ejecutivo únicamente promulgando y ejecutando leyes expedidas por la Asamblea parlamentaria; y al órgano judicial interviniendo únicamente en los casos de controversia. Motivo por el que este autor considera que la política del Estado de Derecho contemporáneo debe apuntar hacia la colaboración de poderes, principio que podría ser configurado en el plano que nos incumbe como colaboración de servicios bibliotecarios y de información.

Principio que puede ser respaldado para ofrecer un mejor acceso a las publicaciones gubernamentales mediante la práctica amplia y sistemática de la 
cooperación bibliotecaria gubernamental; es decir, el enlace organizado que debe unir a la comunidad bibliotecaria que asiste al Gobierno en sus tres diferentes dimensiones políticas que marcan la división o la separación de poderes. Para tal efecto es posible poner en marcha la conexión cooperación bibliotecaria e información gubernamental a través de las cinco tareas que Hernon y McClure ${ }^{49}$ consideran al respecto: 1] el almacenamiento cooperativo de colecciones, 2] el acceso al poco uso de material de la biblioteca, 3] la selección, adquisición y proceso cooperativos, 4] la entrega de documentos y 5] el servicio de referencia. La tecnología electrónica aplicada al quehacer bibliotecario y la variedad de productos y sistemas de información electrónica gubernamental pueden facilitar hoy en día esa colaboración.

Distinguir las facultades o las atribuciones políticas del presidente de la Nación por parte del profesional de la bibliotecología significa establecer algunos criterios de certeza para contar con mejores elementos sobre: 1] la naturaleza de los fondos bibliográficos a desarrollar, 2] la formulación de los procedimientos necesarios para realizar la organización documental, 3] la gama de servicios a ofrecer por parte del personal bibliotecario, y 4] la propuesta de colaboración de servicios bibliotecarios y de información entre la biblioteca presidencial y otras instancias bibliotecarias de carácter gubernamental que se hallan distribuidas en el complejo aparato de la Administración Pública. Que en suma servirán para orientar a ese profesional en la elaboración del «proyecto de trabajo» necesario para convencer a la autoridad correspondiente respecto a la creación y/o el desarrollo de ese tipo de unidad de información. Ofrecer servicios bibliotecarios y de documentación a quien tiene la responsabilidad superior de desempeñar la función política del órgano constitucional que dirige los destinos de una Nación significa, pues, conocer los perfiles político-constitucionales del titular del Ejecutivo Federal. Documento administrativo que podría estar fundamentado en los valores de interés público e interés nacional que persigue el titular de la Presidencia de la República. Fesler en relación con el primero asevera:

El interés público es un ideal. Es para los administradores lo que la objetividad para los investigadores: es algo que buscar, aunque se alcance imperfectamente, algo que no se debe desdeñar porque no se alcance el logro. Si no hay interés público, debemos renunciar a la idea de los ideales. El interés público no es algo que

49 Peter Hernon; McClure, Charles R., Public access to governmant information: issues, trends, and strategies, Norwood, New Jersey: Ablex Publishing Corporation, 1988, p. 349. 
podamos tener en las manos, ni algo cuya cultura, anchura y peso pueda medirse. $^{50}$

Sin embargo percibimos bien cuando este interés está en peligro o es afectado negativamente. En este sentido la biblioteca presidencial debe subordinarse al quehacer que lleva a cabo el Ejecutivo. Esta subordinación se extiende a todos aquellos actos de administración bibliotecaria orientados a respaldar el funcionamiento eficaz del aparato que tiene a cargo la «promulgación y ejecución de las leyes», prerrogativas de interés público en tanto que las leyes son las que regulan la organización y la marcha de los servicios públicos administrados por el Gobierno Federal para satisfacer las necesidades de la población, incluyendo, por supuesto, las necesidades colectivas de servicios públicos bibliotecarios destinados a los diversos grupos sociales.

Dentro de la dinámica de la política exterior, trabajo de acción política que apunta hacia la elaboración de programas estratégicos que permitan defender a escala regional e internacional los intereses nacionales, es factible también encontrar elementos orientadores para formular políticamente el «proyecto de trabajo» que exprese la creación o la continuación de una biblioteca presidencial. Lo que se intenta explicar es que la frase «defensa de los intereses de la Nación», implica la necesidad de reconocer el peso especifico que tiene la información organizada que el personal de esa biblioteca puede buscar, localizar y ofrecer en materia de política pública, externa e interna. Política que tendería a mejorar, fortalecer y consolidar el bienestar integral del Pueblo en su vida diaria. Pensamos que los servicios bibliotecarios presidenciales y otros de carácter gubernamental, pueden cooperar, como factores de información documental permanente, en el proceso de formación y formulación de políticas externas.

Dada la importancia que tienen esos servicios, la precaria planificación política externa de algunas naciones podría ser subsanada mediante el uso sistemático de la información organizada del que esa biblioteca podría disponer. El estudio, el análisis y la discusión que entraña la defensa de un determinado interés nacional, sugiere que el líder del Poder Ejecutivo, además de su personal auxiliar, haga un uso intenso y sistemático de la información; los rasgos de continuidad y coherencia, de ajustes y cambios de toda política exterior formulan también que se base en ese recurso que el centro bibliotecario tiene como responsabilidad brindar cotidianamente.

50 James W. Fesler, "El Estado y su estudio: el todo y las partes", en Administración pública: el estado actual de la disciplina, Lynn, Naomi B.; Wildavsky, Aaron (Compiladores), México: Colegio Nacional de Ciencias Políticas y Administración Pública: Fondo de Cultura Económica, 2001, p. 146. 
Así, en virtud de que los pronunciamientos y las decisiones del Ejecutivo en el plano de la política exterior reflejan compromisos y posicionamientos, valores e intereses de la comunidad a la que representa, el personal a cargo del servicio de la biblioteca presidencial debe estar consciente de esa realidad de poder en la que se encuentra inmerso. El juego de intereses cruzados y de ideas contradictorias que evidencian al contexto político, tanto interno como externo de un país, es un referente más sobre el que es factible sostener la existencia imprescindible de la biblioteca al servicio del presidente de la República. Los desafíos concernientes a la política exterior no pueden ser acometidos sólo con datos superficiales; es decir, con proyectos desarticulados y alejados de la realidad, sino con información amplia y profunda en torno del interés nacional correspondiente. La variedad de problemas en materia de política exterior, y la dificultad para reunir la información necesaria para solucionarlos complica a menudo la toma de decisiones. En este sentido una biblioteca presidencial es un mecanismo eficaz, si se la provee de los recursos necesarios, para atenuar el obstáculo que representa la ignorancia por falta de conocimiento sobre un determinado tema; y en consecuencia para contribuir a moldear y a perfeccionar las decisiones políticas del presidente de la República.

Como concepto funcional, el de «biblioteca presidencial», en contraste con el de «biblioteca parlamentaria», se encuentra sin duda en un estadio embrionario, pues aún en la literatura bibliotecológica es un fenómeno incierto; en consecuencia, su valor como importante servicio bibliotecario para practicantes, docentes e investigadores ha pasado casi inadvertido. En este sentido, reconocemos que los trazos de algunas fronteras claras alrededor de su presencia en el seno del Poder Ejecutivo resultan todavía no sólo tenues sino también subjetivos. Empero si ratificamos la idea sobre la necesidad de esa biblioteca como un sistema de apoyo documental imprescindible en el contexto de quien encabeza ese poder político, entonces resulta apropiado adherirnos a lo que apunta $A \operatorname{costa}^{51}$ para el caso mexicano:

Es incuestionable que la Presidencia de la República requiere de órganos de apoyo técnico que auxilien al Ejecutivo Federal en el desempeño de las importantes funciones del Jefe de Estado y de Gobierno de nuestro país.

O como se asienta en Artículo $8^{\circ}$ de la Ley Orgánica de la Administración Pública Federal al referirse a los recursos que debe tener a su alcance la figura presidencial mexicana:

51 Miguel Acosta Romero, Compendio de derecho administrativo, México: Editorial Porrúa, 2003, p. 142 
contará con las unidades de asesoría, de apoyo técnico y de coordinación que el propio Ejecutivo determine, de acuerdo con el presupuesto asignado a la Presidencia de la República. ${ }^{52}$

Desde este vértice normativo es posible aseverar que la biblioteca presidencial puede y debe ser un importante órgano dinámico de apoyo en el plano de las tareas de interés público que realiza el presidente en cumplimiento de sus facultades y obligaciones constitucionales, pues como reconoce Dwyer,

[...] dentro de estos deberes, la autoridad del presidente es amplia y él puede publicar cualquier forma de directiva que él juzgue necesario. Cuando están basadas en autoridad constitucional o estatutaria, estas directivas tienen fuerza de ley. Los bibliotecarios e investigadores están familiarizados con los dos más prominentes de estos instrumentos, las órdenes ejecutivas y las proclamaciones presidenciales. ${ }^{53}$

Pero no es suficiente que bibliotecarios e investigadores se habitúen en especial a esos documentos oficiales que reflejan el poder de la función ejecutiva de las leyes, también es necesario que se relacionen con el mundo real de lo que implica la gestión de la biblioteca al servicio del representante general de los intereses de la Nación. Queda entonces pendiente el esfuerzo del profesional de la bibliotecología por cultivar esta línea de investigación con amplitud y profundidad.

\section{Conclusiones}

Es factible sustentar la biblioteca presidencial, como puede ser también el caso de la biblioteca parlamentaria y otros tipos de bibliotecas gubernamentales distribuidas en el aparato de la Administración Pública Federal, sobre bases teóricas combinadas tanto de la razón bibliotecológica como de la razón politológica. Esta contextura cognitiva muestra la cualidad de cruzar los límites tradicionales de estudio y análisis, de descripción y reflexión, de juicio y opinión, referentes a fenómenos inherentes a nuestra disciplina (la bibliotecología) y a la práctica de nuestra profesión (la biblioteconomía).

52 México [Leyes], Ley Orgánica de la Administración Pública Federal, vigente al 11 de abril de 2005, (citado 4 de junio de 2005), disponible en Internet: http://info4.juridicas.unam.mx/iju$\mathrm{re} / \mathrm{fed} / 164 / 9 . \mathrm{htm}$ ? $\mathrm{s}=$ Journal of Government Information. 29 (2002): 410-419. 
El paradigma de la biblioteca presidencial estadounidense es un referente sugestivo a considerar en el cosmos de esta categoría de centro bibliotecario acotado de un determinado país, pero no es el modelo que se sugiere para crear o continuar el desarrollo de bibliotecas para asistir al presidente de una República inmersa en un Estado que se rige por un derecho vigente. El prototipo que se propone es el de la biblioteca presidencial en activo al servicio del Titular del órgano ejecutivo de la República, es decir, para apoyarlo durante el ejercicio de sus actividades y funciones como tal. Esto implica pensar acerca del servicio de biblioteca para asistir al presidente durante su gestión como primer mandatario de la nación, con la cooperación bibliotecaria de otras importantes bibliotecas gubernamentales.

En el marco del principio de información la institución bibliotecaria presidencial se concibe como un espacio necesario para la toma de decisiones políticas en el nivel tanto de la Jefatura del Estado como de la Jefatura de Gobierno, estructura del Poder Ejecutivo que configura el ejercicio de las funciones que desempeña la institucionalidad de la Presidencia de la República. Esta división de poder político es una forma que permite identificar la importancia, la necesidad y el influjo que las bibliotecas presidenciales pueden y deben tener entre quienes gobiernan y aplican el poder del Estado. De este modo el servicio bibliotecario presidencial se podría poner en práctica en todos aquellos países con régimen de gobierno republicano, forma gubernamental de los Estados del continente americano, con excepción de Canadá y parte del Caribe, que tienen un régimen parlamentario.

Los servicios bibliotecarios presidenciales pueden girar, según nuestro análisis, en torno de dos dimensiones de razonamiento, en la dinámica de sus actos políticos y en el desarrollo de las facultades y obligaciones constitucionales de quien ha sido electo por el pueblo por un determinado periodo. Por lo tanto se propone que la solidez de la biblioteca presidencial en activo esté ligada, dentro de los contornos sujetos por la ley, a los actos políticos y, por ende, al aparato de acción gubernamental del poder público que dirige el Titular del Ejecutivo Federal. En este sentido se piensa que una teoría de la biblioteca presidencial implica la construcción de una teoría bibliotecológico-política de este género de organismo bibliotecario gubernamental, el cual debe desarrollar y organizar las colecciones documentales pertinentes y ofrecer una serie de servicios que apunten a contribuir en la toma de decisiones presidenciales, supeditadas al interés público y el interés nacional.

Finalmente, en virtud de que la Presidencia de la República es la estructura y la posición política más destacada de la organización del Estado, es necesario pensar en la creación, la organización o, si es el caso, en la continuación de un mejor desarrollo correspondiente a un servicio de biblioteca 
presidencial eficaz, moderna, el cual se complemente y caracterice por trabajar en torno de la tendencia digital, a tal grado de configurar en la teoría y la práctica la noción de biblioteca presidencial digital. Las funciones y las actividades que se realizan en los cuadrantes de la jefatura de Estado y la jefatura de Gobierno exigen satisfacer plenamente las necesidades de información. Acto que favorezca, mediante el binomio colecciones-servicios de la biblioteca presidencial, la visión de liderazgo nacional e internacional del presidente sobre asuntos políticos, económicos, sociales, culturales e ideológicos. 